\title{
AVALIAÇÕES FINAIS SOBRE O PNE 2001-2010 E PRELIMINARES DO PNE 2014-2024
}

DONALDO BELLO DE SOUZA

\section{RESUMO}

O presente artigo visa a discutir os resultados de algumas avaliações acadêmicas sobre a implantação do Plano Nacional de Educação (PNE) 2001-2010, assinalando aspectos de seu processo de elaboração e aprovação e das análises a respeito do plano sancionado, que apontam para avaliações preliminares do PNE 2014-2024. Tomando por base a revisão da literatura, conclui-se não haver consenso sobre o êxito daquele primeiro PNE, quer entre os estudos de maior abrangência analítica, quer entre esses $e$ as avaliações que enfocam o exame das decisões relativas a determinadas etapas e modalidades da educação básica, essas consensualmente negativas em termos de resultados, impactos ou efeitos observados. Comparativamente ao primeiro plano, ressalta-se, ainda, que a literatura que versa acerca do novo PNE sugere estar mais atenta ao monitoramento do seu desenvolvimento inicial e futuro.

PALAVRAS-CHAVE PLANO NACIONAL DE EDUCAÇÃO • METAS EDUCACIONAIS • AVALIAÇÃO DE POLÍTICAS PÚBLICAS • GESTÃO DEMOCRÁTICA DA EDUCAÇÃO. 


\section{RESUMEN}

El presente artículo tiene el propósito de discutir los resultados de algunas evaluaciones académicas sobre la implantación del Plano Nacional de Educação (PNE) 2001-2010, así como de señalar aspectos de su proceso de elaboración y aprobación y de los análisis del plan sancionado, que apuntan hacia evaluaciones preliminares del PNE 2014-2024. Tomando como base la revisión de la literatura, se concluye que no hay un consenso sobre el éxito del primer PNE, sea entre los estudios de mayor amplitud analítica, sea entre éstos y las evaluaciones que enfocan el examen de las decisiones relativas a determinadas etapas y modalidades de la educación básica, éstas consensualmente negativas en lo que se refiere a resultados, impactos o efectos observados. En comparación con el primer plan, se destaca asimismo que la literatura acerca del nuevo PNE sugiere que está más atenta al monitoreo de su desarrollo inicial y futuro.

PALABRAS CLAVE PLANO NACIONAL DE EDUCAÇÃO • METAS EDUCATIVAS - EVALUACIÓN DE POLÍTICAS PÚBLICAS • GESTIÓN DEMOCRÁTICA DE LA EDUCACIÓN.

\section{ABSTRACT}

The present article aims at discussing the results of some academic evaluations of the implementation of the Plano Nacional de Educação (PNE) for 2001-2010. It highlights aspects of its process of elaboration and approval as well as aspects of the analyses of the endorsed plan that lead to the preliminary evaluations of the 2014-2024 PNE. Based on the revised literature, the conclusion is that there is no consensus on the success of the first PNE, neither among broader analytical studies, nor between these and the evaluations focusing on the examination of the decisions regarding the different stages and modalities of basic education, the latter being consensually negative in terms of results, impacts or effects. Compared to the first plan, it is worth noting that the literature concerning the new PNE suggests a more careful monitoring of its initial and future development.

KEYWORDS PLANO NACIONAL DE EDUCAÇÃO • EDUCATIONAL GOALS - EVALUATION OF PUBLIC POLICIES - DEMOCRATIC MANAGEMENT OF EDUCATION 


\section{INTRODUÇÃO}

É possível afirmar que a avaliação stricto sensu de planos de educação consiste em um importante componente do processo de planejamento (KIPNIS; ALGARTE, 2001) e, a um só tempo, em mecanismo que viabiliza o acompanhamento, a análise e o julgamento da execução de todas as suas fases. Isso significa considerar a avaliação das políticas educacionais como um processo que implica interatividade e negociações, marcado por certa progressibilidade (BONAMINO et al., 2006), expondo, portanto, dimensões políticas, pois, antes de tudo, resulta de uma construção social e, por conseguinte, da atribuição de valores (CORREIA, 2010; FARIA, 2005; FIGUEIREDO; FIGUEIREDO, 1986).

Nesses termos, a avaliação sistematizada (BONNIOL; VIAL, 2001) de planos de educação passa a ser entendida não apenas como instrumento articulado à correção dos seus rumos pelos governos, útil aos processos de regulação das políticas públicas (BARROSO, 2006), mas como forma política voltada à prestação de contas dos governos à sociedade, com vistas ao conhecimento de seu desempenho, resultados, impactos e efeitos (DRAIBE, 2001). 
Todavia, a avaliação dessas políticas vem apresentando grandes desafios para a área educacional, a começar por sua complexidade teórica e, em especial, metodológica, passando pela diversidade de processos participativos que pode demandar e, ainda, em função da amplitude dos seus desdobramentos institucionais e, de uma forma mais geral, sociais (DOURADO, 2010). Além disso, parece que no Brasil não há uma tradição de valorização dos resultados dos processos avaliativos que, por exemplo, retroalimentem o planejamento educacional (BONAMINO et al., 2006), o que minora ainda mais a sua importância institucional e sociopolítica, configurando formal a previsão do acompanhamento e avaliação nos planos de educação nacionais e infranacionais.

No que tange ao Plano Nacional de Educação (PNE) 20012010, observa-se que a lei que o regulamentou - Lei n. 10.172, de 09 de janeiro de 2001 -, determinou que a "A União, em articulação com os estados, o Distrito Federal, os municípios e a sociedade civil" (BRASIL, 2001, Art. $3^{\circ}$, caput) deveria proceder à efetivação de avaliações periódicas relativas à implementação desse plano nacional, principiando-as no "quarto ano de vigência desta Lei” (BRASIL, 2001, Art. $3^{\circ}, \S^{\circ}$ ), vindo a pressupor acompanhamento e avaliação sistemáticos, constituindo-se em subsídio estratégico e indispensável ao monitoramento e regulação do desenvolvimento das políticas públicas associadas a esse tipo de planejamento educacional, assim como em possibilidade de participação sociopolítica e transparência institucional.

No entanto, conforme examinado mais a diante, do ponto de vista acadêmico, as avaliações stricto sensu acerca da implementação do PNE 2001-2010 se mostram quantitativamente reduzidas e limitadas a algumas das etapas da educação básica e de suas modalidades de ensino, começando a se tornar mais evidentes no limiar de 2009, às vésperas da realização da I Conferência Nacional de Educação (Conae), ${ }^{1}$ pautadas em dados resultantes de algumas das avaliações institucionais promovidas, por exemplo, pelo Ministério da Educação (MEC), embora essas tenham sido iniciadas em meados da vigência daquele plano por meio de importantes trabalhos, como o de Abicalil (2007), Brandão (2006) e Dourado (2006).
1 Conforme será visto mais adiante, a I Conae foi realizada de 28 de março a 10 de abril de 2010, para subsidiar a elaboração de um Projeto de Lei (PL) para o PNE 2011-2020 (BRASIL, 2010) atual PNE 2014-2020 (BRASIL, 2014). 
2 Trata-se de um levantamento exaustivo realizado por Souza e Sousa (2012) acerca dos planos de educação no Brasil, inicialmente cobrindo o período de 1996 a 2010 e, mais recentemente, abarcando o quadriênio 2011-2014, em um de levantamento assistemático.
Já no início da década de 2010, começaram a despontar as primeiras avaliações lato sensu concernentes ao novo PNE, de início visando ao Projeto de Lei (PL) n. 8.035, de 20 de dezembro de 2010 (BRASIL, 2011), originalmente articulado ao planejamento educacional para o período 2011-2020, para, algum tempo depois, deter-se na sua versão final aprovada por lei, cobrindo o decênio 2014-2024 - Lei n. 13.005, de 25 de junho de 2014 (BRASIL, 2014). Essas avaliações consistem em estudos analíticos preliminares que, embora não se pautem nos resultados, impactos ou efeitos desses instrumentos, mesmo porque, dada a sua incipiência, ainda não se consubstanciam nos sistemas educacionais, visam aos ajuizamentos e valorações do conteúdo político ou técnico do texto do plano propriamente dito, ou, prospectivamente, de suas potenciais repercussões, motivo pelo qual são aqui categorizadas como avaliações lato sensu, distinguindo-se, portanto, dos processos avaliativos sistematizados que caracterizam as avaliações stricto sensu, primordiais ao desenvolvimento das políticas públicas, em particular no campo do planejamento educacional.

Assim, o presente artigo pretende discutir os resultados de algumas das avaliações stricto sensu, acadêmicas - e não institucionais -, do PNE 2001-2010, também assinalando aspectos de seu processo de elaboração, aprovação e análises sobre o plano sancionado, apontando estudos avaliativos lato sensu preliminares, também acadêmicos, sobre o PNE 20142024 e implicações de seu acompanhamento e avaliação, tomando por base a revisão de uma extensa literatura direta e indiretamente relacionada a esses dois planos, publicada no Brasil no período de 1996 a $2014 .^{2}$

Para tanto, na próxima seção se realiza uma breve discussão conceitual acerca do binômio plano-planejamento, além da caracterização de alguns aspectos históricos relacionados ao planejamento educacional no Brasil. Na terceira seção, enfocam-se as análises de duas propostas elaboradas ao final da década de 1990 para o PNE 2001-2010, de autoria, respectivamente, da sociedade civil organizada e do Poder Executivo federal, para, nas duas seções seguintes, discutir, respectivamente, as reflexões teóricas sobre a versão final 
desse plano aprovada por lei e a avaliação acadêmica de sua implantação propriamente dita. Na sequência, estabelecem-se algumas considerações acerca do processo de elaboração e aprovação do novo PNE, a vigorar no decênio 2014-2024, pontuando-se algumas das tendências analíticas que o enfocam, de modo a, na sétima e última seção, à guisa de conclusão, destacarem-se os resultados gerais das análises sobre aquele primeiro PNE e, ainda, os desafios postos ao acompanhamento e avaliação do novo plano. ${ }^{3}$

\section{PLANEJAMENTO E PLANOS DE EDUCAÇÃO NO BRASIL}

Diferentes concepções sobre o que é planejamento da educação, em que medida distingue-se dos planos de educação, assim como o lugar que estes ocupam no processo de planejamento propriamente dito, há muito coexistem, quer nas políticas públicas para a área, quer nas discussões estabelecidas no meio acadêmico, o que, em larga medida, condiciona tanto a ação do Estado e dos governos no campo educacional quanto propriamente sua análise científica (por exemplo, histórica, sociológica e política).

Para Cury (1998, p. 164), um plano pode ser considerado

[...] um programa de realizações para ser cumprido e executado em um certo período (definição cronológica), dentro de objetivos a serem atingidos e para os quais se pleiteiam os meios, inclusive pecuniários, necessários para a implementação adequada.

perspectiva igualmente compartilhada por Bordignon (2014, p. 33), que o entende como:

[...] o desenho, o projeto do caminho a seguir, das etapas (metas) e ações a empreender (estratégias) na caminhada para alcançar o futuro desejado. É o documento formal que consolida as decisões tomadas no processo de planejamento. O plano se configura, portanto, num registro escrito, apresentado sob a forma de um documento aprovado, na instância própria de competência legal.
3 Registram-se os agradecimentos pelas importantes sugestões advindas da leitura atenta deste artigo por parte da colega professora Dra. Neusa Chaves Batista, docente da Faculdade de Educação da Universidade Federal do Rio Grande do Sul (UFRGS) 
Assim, um plano diferenciar-se-ia do planejamento propriamente dito na medida em que, enquanto o primeiro "coordena, racionaliza e dá unidade de fins à atuação do Estado, este garante a coerência entre meios e fins, sendo expressão da política geral do Estado" (MARTINS, 2012, p. 96), motivo pelo qual os planos podem cumprir diversas funções nas instituições políticas, econômicas e sociais, dependendo do seu contexto de elaboração e da correlação de forças sociais que os ensejou (BORDIGNON, 2014; VIEIRA, 2014; VIEIRA; ALBUQUERQUE, 2001). Nos tempos atuais, o planejamento passa a ser entendido, portanto, menos como a produção de um documento (o plano propriamente dito) e mais como um processo (MARTINS, 2012), afigurando-se, em última análise, em um ato de intervenção técnica e política (KUENZER; CALAZANS; GARCIA, 2003).

Em termos históricos, é praticamente consensual que a noção de plano de educação, relacionada à ideia de organização de um sistema de educação nacional, fez-se notar pela primeira vez no Brasil no Manifesto dos Pioneiros da Educação (MANIFESTO..., 2006), em 1932, inaugurando reflexões que se estendem até os dias atuais sobre a formulação e implantação de políticas públicas que se insiram em um quadro de maior racionalidade e sistematização, de modo a superar ações tendenciosamente experimentais, intuitivas, fragmentadas ou desarticuladas (VIEIRA, 2014; MARTINS, 2012; MENDONÇA, 2002; DIDONET, 2000, 2001; AZANHA, 1993, 1998).

Todavia, da década de 1930 até o limiar do século XX, sabe-se que não foram muitos os momentos de elaboração ou implementação, de fato, de planos de educação de abrangência nacional no Brasil, e que tais planos implicaram pouca mobilização sociopolítica. A vertente nacional desenvolvimentista que marcou a década de 1930 influenciaria as políticas públicas de educação até a década de 1970, em meio à ascensão do modelo de industrialização (1937-1955), ao longo de sua crise e substituição por um modelo "associado" de desenvolvimento econômico (1955-1968) (RIBEIRO, 1995), desaguando, até os anos iniciais da chamada Nova República, no tecnocratismo e economicismo que caracterizariam os Planos Setoriais de Educação e Cultura (PSECs), 
derivados dos Planos Nacionais de Desenvolvimento (PNDs) (VIEIRA, 2014; VIEIRA; FARIAS, 2007; KUENZER; CALAZANS; GARCIA, 2003; CURY, 1998; HORTA, 1997, 1982), expressão de "uma estratégia de adequação entre o modelo político e o modelo econômico, de base capitalista" (VIEIRA, 2008, p. 117).

A partir do início da década de 1990, de um lado, em meio à reconstrução do federalismo e da democracia (ARRETCHE, 2002a; 2002b), e, de outro, sob os ventos da redefinição do papel do Estado e da própria educação no país (PERONI, 2003; SILVA Jr., 2002; VIEIRA, 2000), o processo de construção de um planejamento educacional sistematizado veio a dar lugar, primeiramente, em 1993, ao Plano Decenal de Educação para Todos (PDET) (BRASIL, 1993) - esquecido antes da metade de sua vigência (OLIVEIRA; ARAÚJO, 2014; CERQUEIRA, 2008; VIEIRA, 2000) -, para, em seguida, engendrar o PNE 2001-2010 (BRASIL, 2001) e, três anos e meio após o término de sua vigência, ao novo PNE (BRASIL, 2014).

\section{ANÁLISES DAS PROPOSTAS PARA O PNE 2001-2010}

As determinações legais quanto ao estabelecimento de um PNE encontram-se postas tanto na Constituição Federal (CF) de 1988 - "A lei estabelecerá o plano nacional de educação, de duração plurianual, visando à articulação e ao desenvolvimento do ensino em seus diversos níveis e à integração das ações do Poder Público [...]" (BRASIL, 1988, Art. 214) -, quanto na Lei de Diretrizes e Bases da Educação Nacional (LDBEN) n. 9.394, de 20 de dezembro de 1996 - "A União incumbir-se-á de: I - Elaborar o plano nacional de educação, em colaboração com os estados, o DF [Distrito Federal] e os municípios" (BRASIL, 1996, Art. 9º I), e, ainda,

A União, no prazo de um ano a partir da publicação desta

Lei, encaminhará, ao Congresso Nacional, o Plano Nacional de Educação, com diretrizes e metas para os dez anos seguintes, em sintonia com a Declaração Mundial sobre educação para Todos (BRASIL, 1996, Art. 87, §1º).

Em paralelo, a Lei n. 9.131, de 24 de novembro de 1995 (BRASIL, 1995, Art. $7^{\circ}, \S 1^{\circ}$ ), incumbiu o Conselho Nacional 
de Educação (CNE) de "subsidiar a elaboração e acompanhar a execução do Plano Nacional de Educação”.

O cumprimento dessas determinações implicou, ao final da década de 1990, a elaboração de duas propostas de PNE, submetidas ao Congresso Nacional por meio do PL n. 4.155, de 10 de fevereiro de 1998 (BRASIL, 1998a), e do PL n. 4.173, de 11 de fevereiro de 1998 (BRASIL, 1998b), de autoria, respectivamente, da sociedade civil organizada e do Poder Executivo federal, caracterizando-se, de acordo com Beisiegel (1999), no primeiro caso pela ampla participação social e pelo caráter de luta política e ideológica que exprimiu, enquanto que, no segundo caso, pelo comprometimento em relação à racionalidade administrativa das políticas educacionais do MEC, tratando-se, portanto, conforme salientado por Cury (1988, p. 162), de "duas formulações opostas quanto às concepções, diretrizes e metas que as norteiam”, embora, na interpretação de Beisiegel (1999, p. 220), ambos os PLs tenham procurado "legitimar-se na ampla participação da sociedade no seu processo de elaboração".

Comparações entre essas duas propostas foram também realizadas, por exemplo, por Calderón e Borges (2014); Davies (2001, 2002, 2014), Souza e Duarte (2014), Oliveira (2005, 2009), Abicalil (2005), Valente e Romano (2002), Didonet (2000) e Beisiegel (1999), em que há consenso de que são propostas substantivamente avessas. Para Didonet (2000, p. 23), essas diferenças se fazem notar desde em aspectos formais, passando pelos estruturais, até aos conteudísticos dos planos:

[...] como o diagnóstico dos problemas educacionais brasileiros, a análise das políticas educacionais vigentes, a identificação das necessidades sociais em termos de metas, a estimativa de recursos necessários para a educação.

Julgamento compartilhado por Beisiegel (1999, p. 229), que sintetiza as propostas em questão como expressão de três perspectivas básicas:

[...] uma primeira, que predomina nas propostas do MEC, denominada por Cury (1998, p. 171) realista-conservadora, fortemente condicionada por limitações impostas pela política econômica do governo da União. Uma segunda 
posição, igualmente presente no documento do MEC, propõe metas mais ambiciosas do que as compatíveis com as orientações atuais da política econômica da União. E, finalmente, uma terceira posição, presente no plano consolidado no II CONED, que estende consideravelmente o alcance das propostas e dos recursos financeiros para todas as áreas dos serviços educacionais e que, por falta de uma expressão mais adequada, poderia ser designada, provisoriamente, como político-utópica.

Para Calderón e Borges (2014) e Valente e Romano (2002), a dualidade estabelecida por esses PLs não consistia apenas em divergências sobre políticas nacionais de educação ou, de modo específico, sobre projetos de escola: "traduziam dois projetos conflitantes de país”. De um lado, de caráter "democrático e popular, expresso na proposta da sociedade”, e, de outro, comprometido com "a política do capital financeiro internacional e a ideologia das classes dominantes, devidamente refletido nas diretrizes e metas do governo" (VALENTE; ROMANO, 2002, p. 98).

O PL n. 4.155/1998 (BRASIL, 1998a), cujo primeiro signatário foi o deputado Ivan Valente, do Partido dos Trabalhadores (PT), e que foi subscrito por mais de 70 parlamentares e por todos os líderes dos partidos de oposição na Câmara dos Deputados e apresentado ao Congresso em 10 de fevereiro de 1998, enquanto que o PL n. 4.173/1998 (BRASIL, 1998b) o foi no dia seguinte, como anexo àquele primeiro plano.

\section{ANÁLISES SOBRE O PNE 2001-2010 APROVADO}

Para Didonet (2000), o PNE 2001-2010 entrou para a história da educação no Brasil distinguindo-se dos demais planos por seis qualificações básicas:

a) é o primeiro plano submetido à aprovação do Congresso Nacional, portanto, tem força de lei; b) cumpre um mandato constitucional (art. 2014 da Constituição Federal de 1988) e uma determinação da Lei de Diretrizes e Bases da Educação Nacional (LDB, art. 87, 1ํ); c) fixa diretrizes, objetivos e metas para um período de dez 
anos, o que garante continuidade da política educacional e coerência nas prioridades durante uma década;

d) contempla todos os níveis e modalidades de educação e os âmbitos da produção de aprendizagens, da gestão e financiamento e da avaliação; e) envolve o Poder Legislativo no acompanhamento de sua execução; e f) chama a sociedade para acompanhar e controlar a sua execução. (DIDONET, 2000, p. 11)

Previsto pela Lei n. 10.172/2001 (BRASIL, 2001), o PNE definiu diagnósticos, diretrizes e 295 objetivos e metas relacionadas ao conjunto de níveis - educação básica (educação infantil, ensino fundamental e ensino médio) e educação superior - e modalidades de ensino - Educação de Jovens e Adultos, Educação a Distância e Tecnologias Educacionais, Educação Tecnológica e Formação Profissional, Educação Especial e Educação Indígena -, tratando também da Formação dos Professores e Valorização do Magistério, do Financiamento e Gestão, além do Acompanhamento e Avaliação do Plano, propugnando a efetivação de uma gestão descentralizada pela via do regime de colaboração entre os entes federativos.

No cômputo geral, considerando-se o trâmite inicial no Poder Legislativo das duas propostas de plano PL n. 4.155/1998 (BRASIL, 1998a) e PL n. 4.173/1998 (BRASIL, 1998b) -, Souza e Duarte (2014) observam que a proposta do Governo Federal foi preponderante na versão final aprovada do PNE em causa, fazendo-se notar, de acordo com Bordignon (2014), entre outras dimensões, tanto na estrutura quanto em $75 \%$ dos seus objetivos e metas do plano, contra $25 \%$ da proposta da Conae. Tal hegemonia, independentemente das particularidades do contexto político da época, é explicado por Oliveira $(2009,2008,2005)$ por meio da tese de que "o 'poder legislativo' para definição das políticas educacionais pela introdução de legislação, via processo legislativo, é preponderantemente do Executivo" (OLIVEIRA, 2009, p. 2). Com isso, 
O fenômeno ocorre não só porque o Poder Executivo usufrui de mecanismos no processo legislativo que the facultam controlar as principais instâncias decisórias do Legislativo, mas também porque o próprio Legislativo subordina suas propostas à aquiescência do Executivo, seja dependendo desse apoio para a aprovação dos seus projetos, seja referendando todos os vetos interpostos pelo Executivo, em muitos casos sem sequer apreciação pelo Congresso Nacional [...]. (OLIVEIRA, 2009, p. 2)

A par da predominância dos interesses do Poder Executivo na esfera do Legislativo, cabe ressaltar que, na época da sanção presidencial, esse PNE recebeu nove vetos que, no seu conjunto, implicaram importantes restrições à gestão e ao financiamento da educação no país, em especial no âmbito do ensino superior (DOURADO, 2010; OLIVEIRA Jr.; BERALDO, 2003; VALENTE; ROMANO, 2002; VALENTE, 2001). Em consequência, o PNE 2001-2010 era muito inconsistente, pois, embora previsse metas de expansão de todos os níveis e modalidades de ensino no país, não presumia custos e tampouco fontes de recursos adicionais para financiá-las (DAVIES, 2014).

Outro ponto a ser destacado é excesso de objetivos e metas, que impõem sérias dificuldades à sua implantação, seu acompanhamento e sua avaliação. Para Dourado (2010, p. 684), esse elevado conjunto de diretrizes e metas

[...] retratam a carência de organicidade interna do Plano, na medida em que várias metas são reiteradas, por vezes superpostas, e, em outros casos, as metas não apresentam a devida articulação interna, especialmente no que se refere a concepções, financiamento e gestão.

Análises das metas de cada um desses níveis, etapas e modalidades, que anteveem as dificuldades que o plano em questão enfrentaria para o cumprimento dos objetivos e metas estabelecidos, podem ser encontradas, entre outros, nos trabalhos de Mendonça (2002), Davies (2002, 2001), Valente (2001) e, com idêntico vigor, em estudos de maior especificidade voltados, por exemplo, à educação infantil (BARRETO, 2003; 
DIDONET, 2003; ARAÚJO, 2002), ao ensino fundamental (TEIXEIRA, 2002b, 2000), ao ensino médio (PINTO, 2004; TEIXEIRA, 2002a) e ao ensino superior (OLIVEIRA Jr.; BERALDO, 2003). No cômputo geral, esses estudos nitidamente convergem para a problemática do financiamento dos objetivos e metas do PNE 2001-2010 (BRASIL, 2001), sinalizando sua insuficiência e sua decorrente, inexequibilidade do plano. Nas palavras de Davies (2002, p. 117), o plano refletiria "muito discurso, nenhum recurso".

No caso da educação infantil, conforme sinalizado por Didonet (2003), as diretrizes e os objetivos e metas correlatos evidenciam a intenção de o PNE torná-la efetiva como primeira etapa da educação básica, porém, de acordo com Barreto (2003), isso somente seria possível se o seu atendimento contasse, de fato, com ações supletivas da União e dos estados, especialmente em municípios que apresentassem necessidades técnicas e financeiras, o que ocorria com acompanhamento da aplicação dos recursos por essas localidades e pelo CNE, conforme indicado por Araújo (2002). No âmbito do ensino fundamental, Teixeira (2002b), igualmente, destaca a importância central do financiamento para que os objetivos e metas do plano fossem alcançados, prevendo que os vetos presidenciais a dispositivos que implicavam ampliação de recursos e investimentos em educação afetariam o atendimento dessa etapa da educação básica. Esses mesmos postulados se repetem para o ensino médio e, sobretudo, para a educação superior, ou seja, no primeiro caso, Pinto (2004) e Teixeira (2002a) enfatizam que para o alcance da quantidade e qualidade de atendimento ao ensino médio definido pelo PNE, em paralelo à continuidade de expansão de sua oferta, em particular pelos estados, implicaria considerar recursos adicionais ao seu financiamento, enquanto que para a educação superior, conforme anteriormente mencionado, o nível mais afetado pelos vetos do Poder Executivo, Oliveira Jr; Beraldo (2003) sinalizam a baixa prioridade do seu atendimento neste PNE, reflexo da pouca importância atribuída ao papel da universidade, especialmente em relação à educação básica. 


\section{AVALIAÇÕES SOBRE A IMPLANTAÇÃO DO PNE 2001-2010}

Avaliações sistematizadas sobre o PNE 2001-2010 vieram a ser promovidas inicialmente pelos Poderes Executivo e Legislativo, com vistas ao exame do cumprimento das suas decisões (objetivos e metas). Na esfera do Poder Executivo, o CNE disponibilizou um importante balanço desse plano sob o título "Indicações para subsidiar a construção do Plano Nacional de Educação 2011-2020", tornando-o público por meio da Portaria CNE/CP n. 10, de 6 de agosto de 2009 (BRASIL, 2009), enquanto que o Instituto Nacional de Estudos e Pesquisas Educacionais Anísio Teixeira do Ministério da Educação (MEC/Inep) difundiu, nesse mesmo ano, a série de três volumes intitulados "Avaliação do Plano Nacional de Educação 2001-2008” (BRASIL, 2009a, 2009b, 2009c). No âmbito do Poder Legislativo, esse PNE foi inicialmente avaliado, no ano de 2004, pela Comissão de Educação e Cultura da Câmara dos Deputados, dando origem ao documento "Avaliação técnica do Plano Nacional de Educação" (BRASIL, 2004), posteriormente, abarcando o período 2004-2006, sendo que os resultados encontram-se registrados no documento “Avaliação do PNE 2004-2006” (BRASIL, 2011).

É possível afirmar que as avaliações acadêmicas relacionadas à implementação do PNE 2001-2010 são quantitativamente reduzidas, mas, ainda sim, é possível agrupá-las em estudos de maior abrangência (AGUIAR, 2010; CURY, 2009; DOURADO, 2010; MARTINS, 2012) ou de maior especificidade, pois esses últimos objetivam exclusivamente determinadas etapas da educação básica - como a educação infantil (GANZELI, 2012b; VIEIRA, 2010) e o ensino médio (BRANDÃO, 2011; KUENZER, 2010) - ou determinadas modalidades de ensino - como a Educação de Jovens e Adultos (EJA) (DI PIERRO, 2010) -, trabalhos que, na sua quase totalidade, são subsidiados pelos resultados da avaliação levada a efeito pelo MEC/Inep 2001-2008 anteriormente aludida (BRASIL, 2009a, 2009b, 2009c).

Conforme já mencionado, os vetos presidenciais, à época da sanção do PNE 2001-2010, notadamente quanto ao seu financiamento, impuseram sérias restrições ao cumprimento das metas e objetivos que, ao lado de outros problemas 
internos e externos ao documento do plano (BRASIL, 2009), acabaram por comprometer a sua exequibilidade, levando-o a transformar-se, conforme predicado por Kuenzer (2010), Cury (2009) e Sguissardi (2006), numa espécie de carta de intenções, coerentemente ao que Valente e Romano (2002), Azevedo (2001) e Monlevade (2001) haviam previsto e originariamente cognominado. Assim, na percepção de Cury, tais vetos configuraram o PNE em questão como um "Plano-anão: grande cabeça e pés pequenos" (2009, p. 26), enquanto que, para Kuenzer (2010), a situação se agravou ainda mais pelo fato de o plano não explicitar os mecanismos de financiamento que, de fato, lhe dariam suporte. Para essa autora, a não clareza quanto a esses parâmetros, em paralelo à ausência de indicadores associados às metas e objetivos, limitam, sobremaneira, a possibilidade de análise e, por conseguinte, de avaliação desse plano, já anteriormente afetada pelo fato de seu diagnóstico inicial não ter contemplado uma criteriosa análise da situação real da educação brasileira, discutindo-a com a sociedade civil, não apenas apresentando dados brutos, mas séries históricas, matrículas por idade, distorção idade-série, relação entre escolaridade, formação profissional e emprego, entre outros, de modo a mostrar como de fato evoluíram o acesso e a permanência nos diferentes níveis, etapas e modalidades de ensino e suas relações com a ocupação e com o acesso à cultura (KUENZER, 2010, p. 853).

Em uma perspectiva relativamente oposta, Martins (2012) registra o seu desacordo a respeito de apreciações mais negativas do êxito desse plano, em especial de que se tenha tornado uma carta de intenções, sinalizando que, enquanto lei, o PNE não pode ser considerado como tal:

Uma lei, ainda que falha, está mais próxima de atingir a eficácia que uma mera carta de intenções, porque a lei, ao contrário desta, já rompeu a barreira da validade, já está em vigor. Seu cumprimento pode ser reivindicado judicialmente (MARTINS, 2012, p. 102).

Para esse autor, considerar o PNE 2001-2010 um fracasso significa "supervalorizar o caráter literal do 'plano como teoria', em 
detrimento da dimensão processual do planejamento. Revela, assim, uma visão estática, não processual do planejamento" (MARTINS, 2012, p. 109). No seu exame, além de parte das metas do PNE terem sido alcançadas ou encaminhadas, foi por meio dele que se retomou o protagonismo da sociedade civil na formulação das políticas públicas de educação, implicando, portanto, aprendizagens sociopolíticas - nesse sentido, perspectiva igualmente compartilhada por Cury (2009) -, motivos que levam Martins (2012, p. 102) a advogar que esse PNE não se constituiu em fracasso, e tampouco em sucesso:

Como o copo meio preenchido, que está parcialmente cheio e parcialmente vazio, o PNE falhou em alguns aspectos e foi bem sucedido em outros. E deixou seu legado, para ser ou não aproveitado pelo próximo plano.

Nessa mesma perspectiva, Aguiar (2010, p. 724) identifica avanços em relação às metas e objetivos desse plano, assim como equívocos, ressaltando que:

[...] a ausência de cumprimento das metas não pode ser atribuída apenas à instância da União. Esta tem responsabilidades concretas, mas os estados, o Distrito Federal e os municípios são corresponsáveis pelos compromissos do Plano. Dependendo da forma como se efetivam as relações entre os entes federados, dos arranjos institucionais e das condições políticas existentes, as metas poderão ser ou não alcançadas.

Dourado (2010), embora reconhecendo o descompasso entre o que foi proposto pelo plano e o efetivado, converge para o mesmo entendimento de Aguiar (2010), esclarecendo que as avaliações que vêm sendo realizadas sobre o PNE 2001-2010 se pautam, predominantemente, no exame das ações do Governo Federal em face das metas e objetivos previstos, não considerando, portanto, as políticas, programas e demais ações relativas aos demais entes federados, completando que esse plano

[...] não se constituiu como base e diretriz para políticas, planejamento e gestão da educação nacional nem foi acionado como tal pelos diferentes segmentos da sociedade civil e política brasileira (DOURADO, 2010, p. 685) 
4 Sobre a tramitação do PNE 2001-2010 no Poder Legislativo ver por exemplo, Peroni e Flores (2014) Oliveira (2009, 2005), Dourado (2010), Valente e Romano (2002) Didonet (2000) e Valente (2001) enquanto que no Poder Executivo, além desses mesmos estudos, os de Oliveira Jr. e Beraldo (2003) e de Mendonça (2002)

5 Vale enfatizar que o levantamento

documental que resultou na identificação dos estudos aqui mencionados, indicado na seção introdutória deste artigo, não revelou avaliações acadêmicas sobre o PNE 2001-2010 que enfocassem o ensino fundamental, a educação superior e modalidades de ensino, a não ser referente à EJA (SOUZA; SOUSA, 2012)
Não obstante o fato de se ter constituído "em um instrumento de luta em prol da construção das políticas" (DOURADO, 2010, p. 689). Para esse autor, tal limitação se apresenta como resultado dos problemas que marcaram o processo de tramitação do plano, ${ }^{4}$

[...] da ausência de centralidade conferida a ele [ao PNE] na efetivação de políticas, dos limites político-econômicos vigentes à regulamentação da ação dos entes federados sob a ótica da cooperação e colaboração, como previsto na Constituição Federal de 1988 [...] (DOURADO, 2010, p. 693).

Já os estudos acadêmicos que visam a avaliações específicas sobre o PNE 2001-2010, no sentido de privilegiarem determinadas etapas e modalidades da educação básica, revelam o não cumprimento da maior parte das decisões associadas à educação infantil, ao ensino médio e à EJA. ${ }^{5}$

Quanto à educação infantil, o estudo de Ganzeli (2012b), que contempla as metas vinculadas à sua oferta e gestão, destaca, entre outros aspectos, preocupações com a sua expansão e melhoria no padrão de atendimento, cujos problemas se fazem notar, por exemplo, na redução do atendimento de crianças em tempo integral nas creches (de 61,9\% em 2000 para $60,3 \%$ em 2007) e na não elevação da taxa de escolarização bruta municipal em creche (em 2007, apenas $2,6 \%$ dos municípios apresentavam taxa superior a $50 \%$ e em pré-escola (em 2007 , apenas $16,4 \%$ dos municípios apresentavam taxa superior a $80 \%$ ) para os $100 \%$ previstos no plano. Para Viera (2010), que além de ter tomado por base as metas relativas ao acesso à educação infantil e também considerou aquelas relativas à formação e valorização dos profissionais que atuam nessa etapa da educação básica e aos convênios com creches e pré-escolas, o crescimento do atendimento de crianças em creches no período 2001-2008, da ordem de $8,6 \%$, não foi suficiente para alcançar os $50 \%$ de matrículas de crianças de 0 a 3 anos, previstos pelo PNE para 2010, alcançando apenas $18,1 \%$, havendo ainda graves desigualdades de acesso associadas à renda, cor e ao meio rural. A um só tempo, Viera (2010) constata a predominância de professoras com Curso Normal atuando na educação infantil e uma 
expressiva participação do setor privado nas suas matrículas que, em 2009 , se situava em $52,1 \%$ nas creches conveniadas e em $28 \%$ na pré-escola, também conveniada.

No que remete ao ensino médio, a avaliação efetuada por Brandão (2011), pautada na análise de sua oferta e seu atendimento, além de também ponderar questões pedagógicas específicas, concluiu que o seu retrato "é pouco animador" (BRANDÃO, 2011, p. 203), uma vez que, em 2009, o número total de matrículas, ao invés de aumentar, decresceu, indicando que não mais da metade dos jovens entre 15 e 17 anos não estão cursando o ensino médio, efeito também associado às baixas taxas de conclusão e qualidade do ensino fundamental. Para Kuenzer (2010), que também analisa dados referentes ao acesso e à qualidade nessa última etapa da educação básica, "os problemas continuam os mesmos" e "a década foi perdida para o ensino médio” (KUENZER, 2010, p. 861), pois, a partir de 2007, passou a ocorrer crescimento negativo de matrículas, implicando, no período 2000-2008, redução de 8,4\%.

Na avaliação realizada por Di Pierro (2010), que examinou os objetivos e metas do PNE 2001-2010 para a EJA, as taxas de analfabetismo no período 2001-2008 não apresentaram recuo satisfatório, ao lado de uma elevação também modesta da média de anos de estudos de escolaridade obrigatória, o que, para a autora, também comprometerá o alcance, em 2015, do "compromisso da iniciativa de Educação para Todos de reduzir pela metade o índice de analfabetismo de 13,6\% registrado em 2000" (DI PIERRO, 2010, p. 946).

\section{AVALIAÇÕES PRELIMINARES SOBRE O PNE 2014-2024}

Ao término da vigência do PNE 2001-2010 (BRASIL, 2001), contabilizou-se a existência, em 2014, de 14 estados, além do Distrito Federal, sem Plano Estadual de Educação (PEE) (54\% do total de 26) (SOUZA; MENEZES, 2014; SOUZA; DUARTE, 2014), e, em 2011, cerca de 2.181 municípios (39,2\% de 5.565) sem Plano Municipal de Educação (PME) (BRASIL, 2012). Somou-se a esses déficits a ausência de um novo PNE que, originalmente, conforme previsto no PL n. 8.035/2010 (BRASIL, 2011), de autoria do Poder Executivo federal, deveria vigorar 
6 Uma análise crítica pormenorizada a respeito do Documento Final da Conae (BRASIL, 2010) pode ser encontrada em Davies (2014, 2010) no qual esse autor, ao analisá-lo, identifica diversas fragilidades no decênio 2011-2020, mas cujo trâmite legislativo consumiu três anos e meio desse período, tendo sido aprovado somente em 25 de junho de 2014, por meio da Lei n. 13.005 (BRASIL, 2014).

De forma similar aos debates que resultaram na proposta da Sociedade Civil para o PNE 2001-2010 (FÓRUM NACIONAL EM DEFESA DA ESCOLA PÚBLICA, 1997), as discussões sobre a elaboração de um novo PNE ocorreram, entre outros espaços, em 2010, na I Conae - cujos debates, além de abarcarem a educação básica e superior, também gravitaram em torno da criação de um Sistema Nacional de Educação -, evento resultante da deliberação da Conferência Nacional de Educação Básica (CONEB), ocorrida em 2008, ambas precedidas, de forma descentralizada, por conferências subnacionais (BORDIGNON, 2014; OLIVEIRA; ARAÚJO; 2014; PERONI; FLORES, 2014). Assim, a expectativa era a de que o Documento Final da Conae (BRASIL, 2010), ${ }^{6}$ que incorporava diversas propostas da sociedade civil para a estruturação do próximo plano - notadamente orientadas por concepções de planejamento com vistas à articulação da gestão democrática das instituições educacionais, da redução da desigualdade e do desenvolvimento integrado à inclusão social (DUARTE; SANTOS, 2014) -, viesse a ser convertido em PL, não vindo a concretizar-se por conta da apresentação, pelo Governo Federal, do PL n. 8.035/2010 (BRASIL, 2011; OLIVEIRA; ARAÚJO, 2014).

O PL n. 8.035/2010 (BRASIL, 2011) veio a ser encaminhado pelo Poder Executivo ao Congresso Nacional no dia 20 de dezembro de 2010, tendo sido votado pela Comissão Especial da Câmara dos Deputados (CEC), à qual estava subordinado, somente um ano e meio depois, em 13 de junho de 2012, acumulando, ao longo do seu trâmite, cerca de 2.905 emendas parlamentares, fruto da mobilização da sociedade civil (OLIVEIRA; ARAÚJO, 2014; PERONI; FLORES, 2014). Conforme sucedido anteriormente com o PNE 2001-2010, as questões relacionadas ao financiamento da educação pública constantes desse novo PNE parecem ter sido, mais uma vez, as mais polêmicas, engendrando algumas importantes disputas parlamentares. De acordo com Oliveira e Araújo (2014), as discussões ocorridas na Câmara dos Deputados, es- 
pecialmente as realizadas por meio de audiências públicas, pautaram principalmente a problemática do financiamento da educação, delineando duas tendências, uma em defesa da aplicação de 10\% do Produto Interno Bruto (PIB) em educação - coerente ao que previa o PL n. 8.035/2010 -, enquanto que a outra defendia a destinação apenas de 7\%. Para Peroni e Flores (2014), tal centralidade decorreria justamente da experiência social pregressa relativa ao PNE 2001-2010, que, conforme visto, veio a ter a sua previsão de recursos vetada, o que determinou a consolidação de uma frente de luta em torno de uma clara destinação de recursos para o financiamento do plano, especialmente pautada nos $10 \%$ do PIB.

Logo após a aprovação do PL n. 8.035/2010 (BRASIL, 2011) pela Comissão de Constituição e Justiça da Câmara dos Deputados, ocorrida em 16 de outubro de 2012 - incluindo a proposta de destinação de $10 \%$ do PIB -, houve o seu encaminhamento ao Senado Federal pela Mesa Diretora da Câmara dos Deputados, no dia 25 desse mesmo mês, onde, na forma de Projeto de Lei da Câmara (PLC) n. 103 (BRASIL, 2012), passou a aguardar a sua avaliação, ${ }^{7}$ cuja votação veio a ser realizada apenas no dia 17 de dezembro de 2013 (PERONI; FLORES, 2014).

Retornando à Câmara dos Deputados, o PL foi finalmente votado no dia 3 de junho de 2014, e, alguns dias depois, em 25 de junho do mesmo ano, sancionado sem vetos pela Presidência da República. No texto sancionado pelo Governo Federal, o novo PNE determina, na vigésima meta, a ampliação do "investimento público em educação de forma a atingir, no mínimo, o patamar de 7\% do Produto Interno Bruto (PIB) do País no quinto ano de vigência desta Lei e, no mínimo, o equivalente a 10\% do PIB no final do decênio" (BRASIL, 2014).

Embora a aprovação desse novo PNE seja recente, alguns estudos já principiaram discussões a seu respeito, sinalizando aspectos da proposta final da Conae (BRASIL, 2010) que deixaram de ser incorporados a esse plano, ou enfocando questões polêmicas atinentes aos seus princípios ou objetivos e metas como, por exemplo, a criação de um Sistema Nacional de Educação, as vinculações do plano com a gestão democrática da educação e, ainda, o financiamento da educação (DAVIES, 2014, 2010; PERONI; FLORES, 2014).
7 Informações circunstanciadas relacionadas a configurações assumidas pelo PLC n. 103/2012 (BRASIL, 2012) ao longo do seu trâmite no Senado, assim como a respeito desse próprio processo legislativo, antes da sua apreciação final pela Comissão de Educação, Cultura e Esporte e pelo Plenário, encontram-se em Silva et al. (2013), enquanto que $\mathrm{o}$ apontamento das fragilidades desse PLC são formuladas por Davies (2014). 
8 Cabe destacar a coletânea organizada por Dourado (2011), que apresenta dez importantes estudos sobre os encaminhamentos que vinham sendo dados a diversos temas constantes do PL n. 8.035/2010
Outros trabalhos, elaborados ao longo do trâmite do PL n. 8.035/2010 (BRASIL, 2011) no Poder Legislativo, alguns ainda referendando as diretrizes do Documento Final da Conae (BRASIL, 2010), trazem à vista análises relacionadas a questões-chave que o novo PNE, para dar conta das demandas educacionais do país, deveria ter contemplado, configurando-se em importantes referências para as análises atuais sobre os direcionamentos impressos nesse novo plano, por exemplo, para a educação infantil (GANZELI, 2012b), a EJA (DI PIERRO, 2010) e o ensino médio (BRANDÃO, 2011; PINTO; AMARAL; CASTRO, 2011; KUENZER, 2010). A par dessas etapas da educação básica, outros estudos vêm estabelecendo ajuizamentos acerca dos problemas que marcam as decisões concernentes à avaliação da educação básica nesse novo plano (OLIVEIRA, 2010), à valorização do magistério (BRITO, 2013), ao financiamento da educação (OLIVEIRA, 2011; AMARAL, 2010) e, por fim, à gestão da educação - privilegiando o planejamento educacional (MARTINS, 2012), a constituição de um Sistema Nacional de Educação - no qual o PNE teria papel articulador estratégico (FERNANDES; BRITO; PERONI, 2012; SAVIANI, 2010a, 2010b; ARAUJO, 2010) -, o regime de colaboração (GANZELI, 2012a; ARAUJO, 2010) e o acompanhamento e controle do plano propriamente dito (OLIVEIRA, 2011). ${ }^{8}$

Nesses termos, em que pese o fato de o novo PNE assentar-se apenas em vinte decisões - distintamente do primeiro plano, que veio a ser constituído por 295 -, no cômputo geral continuam a vigorar os desafios relativos à universalização do conjunto de etapas e modalidades da educação básica, articuladamente à melhoria da sua qualidade; à ampliação, igualmente, da oferta com qualidade do ensino superior, incluindo-se o segmento de pós-graduação; passando pela qualificação e valorização dos profissionais da educação e culminando tanto no asseguramento de condições para a efetivação da gestão democrática quanto na ampliação do investimento público em educação, agora para os almejados $10 \%$ do PIB. 


\section{CONSIDERAÇÕES FINAIS}

Circunscritamente ao universo de referências até aqui inventariadas, é possível afirmar que as análises acadêmicas sobre o PNE 2001-2010 tenderam a concentrar-se mais sobre a sua elaboração e aprovação do que propriamente a respeito da avaliação da sua implantação, expondo consensualidade quanto ao fato de que seu trâmite no Poder Legislativo veio a ocorrer em meio à hegemonia dos interesses do Poder Executivo, interesses esses igualmente manifestos quando na sanção presidencial, consubstanciados por meio de vetos incidentes no seu financiamento.

A um só tempo, os estudos em questão permitem depreender que, mesmo antes da sua implantação, diversas avaliações lato sensu pautadas no texto do plano propriamente dito anteviram dificuldades que o PNE 2001-2010 enfrentaria para o cumprimento das decisões fixadas, convergindo para o entendimento de que os recursos para o seu financiamento se mostravam insuficientes, em larga medida agravado pela ausência da explicitação dos mecanismos de financiamento que dariam suporte ao plano.

Já em termos da implantação do PNE, constata-se que as poucas avaliações stricto sensu levadas a efeito divergem quanto à sua efetividade. No âmbito dos exames de maior abrangência analítica, o êxito do PNE 2001-2010 não é consensual, havendo posicionamentos, de um lado, que advogam o fracasso do plano, inclusive destacando a impossibilidade técnica de avaliá-lo, e, de outro, que ressaltam o mérito de sua expressão jurídica, significado sociopolítico e valor pedagógico que exprime para o processo social e institucional de construção de novos planos de educação. Na esfera dos estudos que pontualmente enfocam o exame das metas e objetivos de determinadas etapas e modalidades da educação básica, tomando como referência resultados das avaliações institucionais realizadas pelo MEC, sua avaliação se revela consensualmente negativa em termos dos resultados, impactos ou efeitos observados.

Comparativamente ao PNE 2001-2010, a literatura que versa sobre o novo PNE sugere estar mais atenta ao monitoramento do seu desenvolvimento inicial, agora levando em 
conta um plano que, em função das grandes fragilidades do seu antecessor, mostra-se tecnicamente mais aperfeiçoado, embora em termos político-educacionais ainda reflita conservadorismos e decisões privatistas da educação.

O acompanhamento e avaliação do PNE 2014-2024, não apenas do ponto de vista da sua versão nacional, mas também ao nível infranacional, consiste em um dos grandes desafios a serem enfrentados na sua implementação. Na esfera nacional, esse plano estabelece que a execução e o "cumprimento de suas metas serão objeto de monitoramento contínuo e de avaliações periódicas" (BRASIL, 2014, Art. 5 ${ }^{\circ}$ caput), a serem institucionalmente realizados pelo MEC, pela Comissão de Educação da Câmara dos Deputados e Comissão de Educação, Cultura e Esporte do Senado Federal, pelo CNE e, ainda, pelo Fórum Nacional de Educação (FNE) (BRASIL, 2014, Art. 5, I a IV). No âmbito infranacional, dispõe que "Os sistemas de ensino dos Estados, do Distrito Federal e dos Municípios criarão mecanismos para o acompanhamento local da consecução das metas deste PNE e dos planos previstos no art. 8-" (BRASIL, 2014, art. $7^{\circ}, \S 3^{\circ}$ ), ou seja, esses entes federados, ao elaborarem, no prazo de um ano, os respectivos PEEs, Plano de Educação do Distrito Federal (PEDF) e PMEs, deverão observar o seu acompanhamento e avaliação em "consonância com as diretrizes, metas e estratégias previstas neste PNE" (BRASIL, 2014, Art. $8^{\circ}$ ).

Por fim, cabe ressaltar que, de modo distinto do primeiro PNE, o novo plano se encontra assentado em objetivos e metas com quantitativos e prazos mensuráveis, trazendo à vista as intenções e ações das políticas educacionais a serem adotadas para a década, contando, ainda, com a indicação de algumas das etapas a serem cumpridas ao longo da sua implementação, o que, em larga medida, viabiliza os processos de acompanhamento e avaliação, quer pelos Poderes Públicos, quer pela sociedade civil, em particular por meio do importante papel a ser cumprido pela agenda das pesquisas em políticas públicas em educação. 


\section{REFERÊNCIAS}

ABICALIL, Carlos Augusto. Plano Nacional de Educação na República Federativa do Brasil: instrumento de retórica ou política pública para a realização do direito à Educação Básica? 2005. 185 f. Dissertação (Mestrado em Educação) - Faculdade de Educação, Universidade de Brasília, Brasília, Distrito Federal, 2005.

PNE: limites e desafios; uma avaliação necessária. Brasília, DF:

Câmara dos Deputados, 2007.

AGUIAR, Márcia Ângela da Silva. Avaliação do Plano Nacional de Educação 2001-2009: questões para reflexão. Educação \& Sociedade, Campinas, v. 31, n. 112, p. 707-727, jul./set. 2010.

AMARAL, Nelson Cardoso. Financiamento da educação básica e o PNE 2011-2020. Retrato de Escola, Brasília, DF, v. 4, n. 6, p. 123-141, jan.jjul. 2010.

ARAÚJO, Gilda Cardoso de. Constituição, federação e propostas para o novo plano nacional de educação: análise das propostas de organização nacional da educação brasileira a partir do regime de colaboração. Educação \& Sociedade, Campinas, v. 31, n. 112, p. 749-768, jul./set. 2010.

ARAÚJO, Regina Magna Bonifácio de. A educação infantil e o Plano Nacional de Educação. In: TEIXEIRA, Lúcia Helena Gonçalves. (Org.). LDB e PNE:

desdobramentos na política educacional brasileira. São Bernardo do Campo: Unesp, 2002. p. 55-66. (Cadernos Anpae, 1).

ARRETCHE, Martha. Federalismo e relações intergovernamentais no Brasil: a reforma de programas sociais. Dados: Revista de Ciências Sociais, Rio de Janeiro, v. 45, n. 3, p. 431-458, 2002a.

Relações federativas nas políticas sociais. Educação \& Sociedade, Campinas, v. 23, n. 80, p. 25-48, set. 2002b.

AZANHA, José Mário Pires. Política e planos de educação no Brasil: alguns pontos para reflexão. Cadernos de Pesquisa, São Paulo, n. 85, p. 70-78, maio, 1993.

Planos e políticas de educação no Brasil: alguns pontos para reflexão. In: BARROS, Roque Spencer Maciel et al. Estrutura e funcionamento da educação básica. 2. ed. São Paulo: Pioneira, 1998. p. 102-123.

AZEVEDO, Neroaldo Pontes de. Política e gestão na educação municipal. In: CONFERÊNCIA NACIONAL DE EDUCAÇÃO, CULTURA E DESPORTO, 1., 2001, Brasília, DF. Anais... Brasília, DF: Câmara dos Deputados, 2001. p. 71-74.

BARRETO, Ângela Maria Rabelo Ferreira. A educação infantil no contexto das políticas públicas. Revista Brasileira de Educação, Rio de Janeiro, v. 8, n. 24, p. 53-65, set./dez. 2003.

BARROSO, João. Introdução: a investigação sobre a regulação das políticas públicas de educação em Portugal. In: (Org.). 0 Estado e a educação: a regulação transnacional, a regulação nacional e a regulação local. Lisboa: Educa, 2006. p. 41-70. 
BEISIEGEL, Celso de Rui. O Plano Nacional de Educação. Cadernos de Pesquisa, São Paulo, v. 29, n. 106, p. 217-231, mar. 1999.

BONAMINO, Alicia; FRANCO, Creso; SOUSA, Sandra Zákia; MAIA, Maurício. Avaliação de políticas educacionais. In: BRASIL. Ministério da Educação. Secretaria de Educação Básica. Pradime: Programa de Apoio aos Dirigentes Municipais de Educa. Brasília, DF: MEC/SEB, 2006. p. 133-176. (Caderno de Textos, 1).

BONNIOL, Jean-Jacques; VIAL, Michel. Modelos de avaliação: textos fundamentais. Porto Alegre: Artmed, 2001.

BORDIGNON, Genuíno. Caminhar da educação brasileira: muitos planos, pouco planejamento. In: SOUZA, Donaldo Bello de; MARTINS, Ângela Maria (Org.). Planos de educação no Brasil: planejamentos, políticas, práticas. São Paulo: Loyola, 2014. p. 29-54.

BRANDÃO, Carlos da Fonseca. PNE passo a passo (Lei n. 10.172/2001): discussão dos objetivos e metas do Plano Nacional de Educação. São Paulo: Avercamp, 2006.

. O ensino médio no contexto do Plano Nacional de Educação: o que ainda precisa ser feito. Cadernos CEDES, Campinas, v. 31, n. 84, p. 195-208, maio/ago. 2011.

BRASIL. Constituição [de 1988] da República Federativa do Brasil. Diário Oficial da União [da] República Federativa do Brasil, Brasília, DF, 5 out. 1988.

BRASIL. Lei n. 9.131, de 24 de novembro de 1995. Altera dispositivos da Lei n. 4.024, de 20 de dezembro de 1961, e dá outras providências. Diário Oficial da União [da] República Federativa do Brasil, Brasília, DF, 25 nov. 1995.

. Lei n. 9.394, de 20 de dezembro de 1996. Estabelece as Diretrizes e Bases da Educação Nacional. Diário Oficial da União [da] República Federativa do Brasil, Brasília, DF, 23 dez. 1996.

. Lei n. 10.172, de 09 de janeiro de 2001. Aprova o Plano Nacional de Educação (PNE). Diário Oficial da União [da] República Federativa do Brasil, Brasília, DF, 10 jan. 2001.

. Lei n. 13.005, de 25 de junho de 2014. Aprova o Plano Nacional de Educação - PNE e dá outras providências. Diário Oficial da União [da] República Federativa do Brasil, Brasília, DF, 26 jun. 2014.

BRASIL. Projeto de Lei n. 4.155, de 10 de fevereiro de 1988. Aprova o Plano Nacional de Educação [Proposta da Sociedade Brasileira]. Diário da Câmara dos Deputados, Brasília, DF, v. 53, n. 42, 12 mar. 1998a.

. Projeto de Lei n. 4.173, de 11 de fevereiro de 1998. Institui o Plano Nacional de Educação [Proposta do Poder Executivo ao Congresso Nacional apensada ao PL 4.155/1998]. Brasília, DF: Câmara dos Deputados, 13 fev. 1998b.

Projeto de Lei do Plano Nacional de Educação (PNE 2011-2020): Projeto em tramitação no Congresso Nacional - PL n. 8.035/2010. Brasília, DF: Câmara dos Deputados, Edições Câmara, 2011. 
BRASIL. Câmara dos Deputados. Projeto de Lei n. 103, de 25 de outubro de 2012, (Projeto de Lei n. 8.035, de 2010, na Casa de origem), de iniciativa da Presidência da República. Aprova o Plano Nacional de Educação - PNE e dá outras providências. Brasília, DF: Congresso Nacional, 2012.

BRASIL. Câmara dos Deputados. Comissão de Educação e Cultura. Avaliação técnica do Plano Nacional de Educação. Brasília, DF: Câmara dos Deputados, 2004. (Série Ação Parlamentar, 294).

. Avaliação do PNE 2004-2006: avaliação do cumprimento das metas do Plano Nacional de Educação (PNE). Brasília, DF: Centro de Documentação e Informação, Edições Câmara, 2011. (Ação Parlamentar, 351).

BRASIL. Conselho Nacional de Educação. Portaria CNE/CP n. 10, de 6 de agosto de 2009. Indicações para subsidiar a construção do Plano Nacional de Educação 2011-2020. Brasília, DF: CNE/CP, 2009.

BRASIL. Instituto Brasileiro de Geografia e Estatística. Diretoria de Pesquisas. Coordenação de População e Indicadores Sociais. Perfil dos municípios brasileiros 2011: pesquisa de informações básicas municipais. Rio de Janeiro: IBGE, 2012.

BRASIL. Ministério da Educação. Instituto Nacional de Estudos e Pesquisas Educacionais Anísio Teixeira. Avaliação do Plano Nacional de Educação 2001-2008: níveis de ensino. Brasília, DF: MEC/INEP, 2009a. v. 1.

Avaliação do Plano Nacional de Educação 2001-2008: modalidades de ensino. Brasília, DF: MEC/INEP, 2009b. v. 2.

. Avaliação do Plano Nacional de Educação 2001-2008: magistério da educação básica e financiamento e gestão educacional . Brasília, DF: MEC/INEP, 2009c. v. 3.

BRASIL. Ministério da Educação. Secretaria Executiva. Conferência Nacional de Educação 2010 - Construindo o sistema nacional articulado de educação: o plano nacional de educação, diretrizes e estratégias de ação. Documento Final. Brasília, DF: MEC, 2010.

BRASIL. Ministério da Educação e do Desporto. Plano Decenal de Educação Para Todos. Brasília, DF: MEC, 1993.

BRITO, Vera Lúcia Alves de. O Plano Nacional de Educação e o ingresso dos profissionais do magistério da educação básica. Educação \& Sociedade, Campinas, v. 34, n. 125, p. 1251-1267, out./dez. 2013.

CALDERÓN, Adolfo Ignácio; BORGES, Regilson Maciel. Construção dos planos nacionais de educação no Brasil: os grupos de articulação de interesses em ação. In: SOUZA, D. B. de; MARTINS, Â. M. (Org.). Planos de educação no Brasil: planejamentos, políticas, práticas. São Paulo: Loyola, 2014. p. 99-123.

CERQUEIRA, Nádia Dorian Souza de. Valorização do magistério: contradições entre os anúncios de políticas governamentais e as medidas efetivadas para a melhoria do trabalho docente no período de 1993-2003 no Município de Alagoinhas-Bahia. 2008. 76 f. Dissertação (Mestrado em Educação) Faculdade de Educação, Universidade Federal da Bahia, Salvador, Bahia. 
CORREIA, José Alberto. Paradigmas e cognições no campo da administração educacional: das políticas de avaliação à avaliação como política. Revista Brasileira de Educação, Rio de Janeiro, v. 15, n. 45, p. 456-592, set./dez. 2010

CURY, Carlos Roberto Jamil. O Plano Nacional de Educação: duas formulações. Cadernos de Pesquisa, São Paulo, v. 28, n. 104, p. 162-180, jul. 1998.

. Por um Plano Nacional de Educação: nacional, federativo, democrático e efetivo. Revista Brasileira de Política e Administração da Educação, Porto Alegre, v. 25, n. 1, p. 13-30, 2009.

DAVIES, Nicholas. Plano Nacional de Educação: muito discurso, nenhum recurso. Universidade e Sociedade, São Paulo, v. 11, n. 25, p. 29-39, dez. 2001.

Plano Nacional de Educação: muito discurso, nenhum recurso. In: TEIXEIRA, L. H. G. (Org.). LDB e PNE: desdobramentos na política educacional brasileira. São Bernardo do Campo: Unesp, 2002. p. 117-143.

. A Conferência Nacional de Educação (Conae) e suas fragilidades. Revista HISTEDBR [online], Campinas, v. 10, n. 39, p. 321-345, set. 2010.

. Fragilidades e desafios do financiamento em planos de educação: 10\% do PIB são a salvação? In: SOUZA, Donaldo Bello de; MARTINS, Ângela. Maria. (Org.). Planos de educação no Brasil: planejamentos, políticas, práticas. São Paulo: Loyola, 2014. p. 183-205.

DI PIERRO, Maria Clara. A educação de jovens e adultos no plano nacional de educação: avaliação, desafios e perspectivas. Educação \& Sociedade, Campinas, v. 31, n. 112, p. 939-959, jul./set. 2010.

DIDONET, Vital. Plano Nacional de Educação (PNE). Brasília, DF: Plano, 2000.

. O Plano Nacional de Educação e os planos estaduais e municipais: uma conquista histórica. Gestão em Rede, Curitiba, n. 33, p. 14-19, nov./dez. 2001.

. A educação infantil no Plano Nacional de Educação. Amae Educando, Belo Horizonte, v. 36, n. 316, p. 6-10, 2003.

DOURADO, Luiz Fernandes. Plano Nacional de Educação: avaliações e retomada do protagonismo da sociedade civil organizada na luta pela educação. In: FERREIRA, N. S. C. (Org.). Políticas públicas e gestão da educação: polêmicas, fundamentos e análises. Brasília, DF: Liber Livro, 2006. p. 21-50.

. Avaliação do Plano Nacional de Educação 2001-2009: questões estruturais e conjunturais de uma política. Educação \& Sociedade, Campinas, v. 31, n. 112, p. 677-705, jul./set. 2010.

. (Org.). Plano nacional de educação (2011-2020): avaliação e perspectivas. Goiânia: Ed. UFG; Belo Horizonte: Autêntica, 2011.

DRAIBE, Sônia Miriam. Avaliação de implementação: esboço de uma metodologia de trabalho em políticas públicas. In: BARREIRA, Maria Cecília Roxo Nobre; CARVALHO, Maria do Carmo Brant de. (Org.). Tendências e perspectivas na avaliação de políticas e programas sociais. São Paulo: IEE/PUC-SP, 2001. p. 13-42. 
DUARTE, Marisa Ribeiro Teixeira; SANTOS, Maria Rosimary Soares. Educação e desenvolvimento: planejamento de ações governamentais e novos modos de regulação social? In: SOUZA, Donaldo Bello de; MARTINS, Ângela Maria. (Org.). Planos de educação no Brasil: planejamentos, políticas, práticas. São Paulo: Loyola, 2014. p. 73-98.

FARIA, Carlos Aurélio Pimenta de. A política da avaliação de políticas públicas. Revista Brasileira de Ciências Sociais, São Paulo, v. 20, n. 59, p. 97-109, out. 2005.

FERNANDES, Maria Dilnéia Espíndola; BRITO, Silvia Helena Andrade de; PERONI, Vera Maria Vidal. Revista Brasileira de Estudos Pedagógicos, Brasília, DF, v. 93, n. 235, p. 565-578, set./dez. 2012.

FIGUEIREDO, Marcus Faria; FIGUEIREDO, Argelina Maria Cheibub. Avaliação política e avaliação de políticas: um quadro de referência teórica. Análise $\mathcal{E}$ Conjuntura, Belo Horizonte, v. 1, n. 3, p. 107-127, set./dez. 1986.

FÓRUM NACIONAL EM DEFESA DA ESCOLA PÚBLICA. Plano Nacional de Educação: proposta da sociedade brasileira [Consolidado na plenária de encerramento do II CONED]. In: CONGRESSO NACIONAL DE EDUCAÇÃO, 2., 1997. Anais... Belo Horizonte: FNDEP, nov. 1997.

GANZELI, Pedro. Plano nacional de educação no Brasil: reflexos sobre o regime de colaboração. In: CONGRESSO IBERO-AMERICANO DE POLÍTICA E ADMINISTRAÇÃO DA EDUCAÇÃO, 3., 2012, Zaragoza, Espanha. Anais... Recife: ANPAE, 2012a.

Plano nacional de educação: implicações para a educação infantil. Revista Exitus, Belém, v. 2, n. 2, p. 77-102, jul./dez. 2012b.

HORTA, José Silvério Baia. Liberalismo, tecnocracia e planejamento educacional no Brasil. São Paulo: Cortez; Campinas: Autores Associados, 1982.

Plano Nacional de Educação: da tecnocracia à participação democrática. In: CURY, Carlos Roberto Jamil. Medo à liberdade e compromisso democrático: LDB e Plano Nacional de Educação. São Paulo: Pioneira, 1997. p. 137-206.

KIPNIS, Bernardo; ALGARTE, Roberto. Planejamento e avaliação educacionais. In: WITTMANN, Lauro Carlos; GRACINDO, Regina Vinhaes (Org.). O estado da arte em política e gestão da educação no Brasil 1991-1997. Campinas: Autores Associados; São Paulo: Anpae, 2001. p. 151-171.

KUENZER, Acácia Zeneida. O ensino médio no Plano Nacional de Educação 2011-2020: superando a década perdida? Educação \& Sociedade, Campinas, v. 31, n. 112, p. 851-873, jul./set. 2010.

KUENZER, Acácia; CALAZANS, Maria Julieta; GARCIA, Walter. Planejamento e educação no Brasil. 6. ed. São Paulo: Cortes, 2003. (Coleção Questões da Nossa Época, 21).

MANIFESTO dos Pioneiros da Educação Nova [1932]. Revista Histedbr On-line, Campinas, n. especial, p. 188-204, ago. 2006. Disponível em <http://www.histedbr. fae.unicamp.br/revista/edicoes/22e/doc1_22e.pdf> Acesso em: 06 nov. 2014. 
MARTINS, Paulo de Sena. Planejamento e plano nacional de educação. Cadernos Aslegis, Brasília, DF, n. 39, p. 91-118, jan./abr. 2012.

MENDONÇA, Erasto Fortes. Plano Nacional de Educação: desdobramentos na política nacional. In: TEIXEIRA, Lúcia Helena G. (Org.). LDB e PNE: desdobramentos na política educacional brasileira. São Bernardo do Campo: UMESP, 2002. p. 13-54. (Cadernos Anpae, n. 1).

MONLEVADE, João Antônio Cabral de. Avaliação e perspectivas do financiamento da educação pública no Brasil. In: CONFERÊNCIA NACIONAL DE EDUCAÇÃO, CULTURA E DESPORTO, 1, 2001, Brasília, DF. Anais... Brasília, DF: Câmara dos Deputados, 2001. p. 43-48.

OLIVEIRA, Dalila Andrade de; ARAÚjO, Heleno. Educação entre os planos de governo e as políticas de Estado: o foco no financiamento e a questão docente. In: SOUZA, Donaldo Bello de; MARTINS, Ângela Maria (Org.). Planos de educação no Brasil: planejamentos, políticas, práticas. São Paulo: Loyola, 2014. p. 167-182.

OLIVEIRA, João Ferreira de. A educação básica e o PNE/2011-2020: políticas de avaliação democrática. Revista Retratos da Escola, Brasília, v. 4, n. 6 , p. 91-108, jan.-jun. 2010.

OLIVEIRA Jr., Lourival Batista de; BERALDO, Antonio Fernando. Vetar é preciso, educar não é preciso: os vetos presidenciais ao Plano Nacional de Educação. Revista Brasileira de Política e Administração da Educação, Piracicaba, v. 19, n. 1, p. 55-80, 2003.

OLIVEIRA, Romualdo Portela de. O Plano Nacional de Educação: algumas questões para debate. Jornal de Políticas Educacionais, Curitiba, n. 9, p. 3-10, jan.jjun. 2011.

OLIVEIRA, Rosimar de Fátima. 0 papel do Poder Legislativo na formulação das políticas educacionais. 2005. 262 f. Tese (Doutorado em Educação) - Faculdade de Educação, Universidade de São Paulo, São Paulo, 2005.

. O papel do poder legislativo na formulação das políticas sobre financiamento da educação. Revista Brasileira de Política e Administração da Educação, Porto Alegre, v. 24, n. 2, p. 235-247, maio/ago. 2008.

. Revisando os mecanismos de formulação do Plano Nacional de Educação: considerações sobre o processo decisório. In: REUNIÃO ANUAL DA ASSOCIAÇÃO NACIONAL DE PÓS-GRADUAÇÃO E PESQUISA EM EDUCAÇÃO, 32., 2009, Caxambu. Anais... Rio de Janeiro: ANPEd, 2009.

PERONI, Vera Maria Vidal. Política educacional e papel do estado no Brasil dos anos 1990. São Paulo: Xamã, 2003.

PERONI, Vera Maria Vidal; FLORES, Maria Luiza Rodrigues. Sistema nacional, plano nacional e gestão democrática da educação no Brasil: articulações e tensões. In: SOUZA, D. B. de; MARTINS, Â. M. (Org.). Planos de educação no Brasil: planejamentos, políticas, práticas. São Paulo: Loyola, 2014. p. 147-166.

PINTO, José Marcelino de Rezende. Financiamento do ensino médio no Brasil: uma abordagem inicial. Trabalho, Educação e Saúde, Rio de Janeiro, v. 2, n. 1, p. 135-152, mar. 2004. 
PINTO, José Marcelino de Rezende; AMARAL, Nelson Cardoso; CASTRO, Jorge Abrahão de. O financiamento do ensino médio no Brasil: de uma escola boa para poucos à massificação barata da rede pública. Educação $\delta$ Sociedade, Campinas, v. 32, n. 116, p. 639-665, jul./set. 2011.

RIBEIRO, Maria Luísa Santos. História da educação brasileira: a organização escolar. 14. ed. Campinas: Autores Associados, 1995.

SAVIANI, Dermeval. Organização da educação nacional: Sistema e Conselho Nacional de Educação, Plano e Fórum Nacional de Educação. Educação $\mathcal{E}$ Sociedade, Campinas, v. 31, n. 112, p. 769-787, jul./set. 2010a.

Sistema nacional de educação articulado ao Plano Nacional de Educação. Revista Brasileira de Educação, Rio de Janeiro, v. 15, n. 44, p. 380-412, maio/ago. 2010b.

SGUISSARDI, Valdemar. Prefácio. In: BRANDÃO, Carlos da Fonseca. PNE passo a passo (Lei n. 10.172/2001): discussão dos objetivos e metas do Plano Nacional de Educação. São Paulo: Avercamp, 2006. p. 13-16.

SILVA, Fernando Mariano da; MONLEVADE, João Antonio Cabral de; QUEIROZ, José Edmar de; BRITTO Tatiana Feitosa de. O Plano Nacional de Educação no Senado: estágio atual. Brasília, DF: Senado Federal, nov. 2013. (Textos para Discussão, 143).

SILVA Jr., João dos Reis. Reforma do estado e da educação no Brasil de FHC. São Paulo: Xamã, 2002.

SOUZA, Donaldo Bello de; DUARTE, Marisa Ribeiro Teixeira. Planos de educação no Brasil: projeções do sistema nacional de educação e suas variantes subnacionais. In: SOUZA, Donaldo Bello de; MARTINS, Ângela Maria (Org.). Planos de educação no Brasil: planejamentos, políticas, práticas. São Paulo: Loyola, 2014. p. 209-232.

SOUZA, Donaldo Bello de; MENEZES, Janaína Specht da Silva. Estudo crítico-exploratório sobre os Planos Estaduais de Educação (PEEs) no Brasil: contribuições para formulações e reformulações decorrentes do novo Plano Nacional de Educação (PNE) - Relatório de pesquisa. Rio de Janeiro: Nephem/Uerj; Neephi/Unirio, jun. 2014.

SOUZA, Donaldo Bello de; SOUSA, Gustavo José Albino de. Planos nacionais, estaduais e municipais de educação no Brasil: balanço quali-quantitativo sobre a literatura acadêmica (1996-2010). Agenda Social, Campos dos Goytacases, v. 6, p. 50-70, 2012.

TEIXEIRA, Beatriz de Bastos. Plano nacional de educação impõe PCNs às escolas. In: CAVALCANTE, A. L.; PEREIRA, J. R.; LIMA, M. J. R.. Plano Nacional de Educação: algumas considerações. Brasília, DF: Núcleo de educação, Cultura, Desporto, Ciência \& Tecnologia da Bancada do Partido dos Trabalhadores na Câmara dos Deputados, 2000.

Ensino médio: perspectivas e limites contidos no PNE. In: TEIXEIRA, L. H. G. (Org.). LDB e PNE: desdobramentos na política educacional brasileira. São Bernardo do Campo: Unesp, 2002a, p. 83-91.(Cadernos Anpae, n. 1). 
. O ensino fundamental no Plano Nacional de Educação. In: TEIXEIRA,

L. H. G. (Org.). LDB e PNE: desdobramentos na política educacional brasileira. São Bernardo do Campo: Unesp, 2002b. p. 67-82. (Cadernos Anpae, n. 1).

VALENTE, Ivan. Plano Nacional de Educação. Rio de Janeiro: DP\&A, 2001.

VALENTE, Ivan; ROMANO, Roberto. PNE: Plano Nacional de Educação ou carta de intenções? Educação \& Sociedade, Campinas, v. 23, n. 80, p. 96-107, set. 2002 .

VIEIRA, Lívia Maria Fraga. A educação infantil e o Plano Nacional de Educação: as propostas da CONAE 2010. Educação \& Sociedade, Campinas, v. 31, n. 112, p. 809-8031, jul./set. 2010.

VIEIRA, Sofia Lerche. Política educacional em tempos de transição (1985-1995). Brasília: Plano, 2000.

- Desejo de reforma: legislação educacional no Brasil Império e República. Brasília, DF: Liber Livro, 2008.

. Planos e políticas educacionais: das concepções às práticas no Brasil. In: SOUZA, Donaldo Bello de; MARTINS, Ângela Maria. (Org.). Planos de educação no Brasil: planejamentos, políticas, práticas. São Paulo: Loyola, 2014. p. 55-72.

VIEIRA, Sofia Lerche; ALBUQUERQUE, Maria Glaucia Menezes. Política e planejamento educacional. Fortaleza: Edições Demócrito Rocha, 2001.

VIEIRA, Sofia Lerche; FARIAS, Isabel Maria Sabino de. Política educacional no Brasil: introdução histórica. Brasília, DF: Líber Livro, 2007.

DONALDO BELLO DE SOUZA

Professor Associado do Departamento de Políticas Públicas, Avaliação e Gestão da Educação na Faculdade de Educação da Universidade do Estado do Rio de Janeiro (DEPAG/ UERJ), Rio de Janeiro, Rio de Janeiro, Brasil donaldosouza@hotmail.com 
